\title{
Validación de nuevos materiales cerámicos a partir de rocas de desecho de minería. Propiedades mecánicas
}

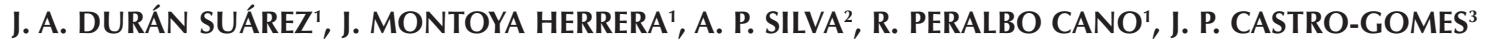 \\ 'Departamento de Escultura, Facultad de Bellas Artes, Universidad de Granada, Edf. Aynadamar, Av. Andalucia s/n, 18071 Granada, España \\ ${ }^{2}$ C-MAST, Centre for Mechanical and Aerospace Science and Technologies, Universidad da Beira Interior, 6201-001 Covilhã, Portugal \\ ${ }^{3} \mathrm{C}-\mathrm{MADE}$, Centre of Materials and Building Technologies, Universidad da Beira Interior, 6201-001 Covilhã, Portugal
}

\begin{abstract}
Se presentan nuevos materiales cerámicos obtenidos a partir de residuos de minería de tungsteno que son extraídos en la región de Beira Interior en Portugal, con nulo aprovechamiento comercial a la par que provocan graves problemas paisajísticos y medioambientales. Los nuevos productos cerámicos, preparados en un amplio rango térmico (desde $800^{\circ} \mathrm{C}$ a $1300^{\circ} \mathrm{C}$ ) han sido evaluados mediante ensayos mecánicos principalmente, aunque también han sido caracterizadas las materias primas de partida: restos de minería de tungsteno y caolín industrial, con los que han sido conformados. Los resultados, que incluyen también una caracterización mineralógica de los productos cerámicos y evaluación morfológica de neoformados mediante microscopía electrónica de barrido, ponen de manifiesto, en primer lugar, la factibilidad de transformar un gran número de estos residuos en productos cerámicos comercializables. Gracias a la experimentación realizada, se puede obtener una pasta industrial con $90 \%$ de residuo sin modificar dramáticamente sus propiedades. Así se pueden generar materiales cerámicos prácticamente sin la presencia de minerales de la arcilla, dada la particular composición de estos residuos de minería con presencia de óxidos ácidos, neutros y básicos.
\end{abstract}

Palabras clave: Cerámica reciclada, Procesamiento, Propiedades mecánicas, Residuos, Microestructura.

\section{Validation of new ceramic materials from tungsten mining wastes. Mechanical properties}

New ceramic materials obtained from tungsten mining wastes, from region of Beira Interior in Portugal, with no commercial use, responsible for landscape and environmental problems are presented. These preshaped new ceramic products, prepared in a wide thermal range $\left(800{ }^{\circ} \mathrm{C}\right.$ to $\left.1300^{\circ} \mathrm{C}\right)$ was evaluated by mechanical test, but also was characterized the starting raw materials: tungsten wastes mining and industrial kaolin. Results, which also include a mineralogical characterization of ceramic products and morphologic evaluation of neoformed by scanning electron microscopy, show firstly, the feasibility of converting a large number of these wastes in marketable ceramics. Thanks to the experimentation carried out, the ability to generate ceramic materials is emphasized, without the presence of mineral clay, due to the particular composition of these waste of mining with content of acid, neutral and basic oxides.

Keywords: Ceramic recycled, Processing, Mechanical properties, Waste, Microstructure.

Cómo citar este artículo: Durán Suárez, J. A.; Montoya Herrera, J.; Silva, A. P.; Peralbo Cano, R. y Castro-Gomes, J. P. (2014): Validación de nuevos materiales cerámicos a partir de rocas de desecho de minería. Propiedades mecánicas, Bol. Soc. Esp. Ceram. Vidr., 53 (6): 279-288. http://dx.doi. org/10.3989/cyv.342014

\section{INTRODUCCIÓN}

La ingente cantidad de residuos procedentes de la actividad extractiva de tungsteno en el área de Panasqueira, Covilhã, Portugal (bloques de diversas dimensiones, gravas y lodos), conlleva graves problemas de índole medioambiental, a pesar de la riqueza que aporta la actividad minera a la economía regional y nacional. Además del impacto negativo en el paisaje es destacable el posible filtrado de restos de metales pesados al suelo y sustratos, debido a procesos de meteorización y alteración de los residuos mineros.

De las minas de esta comarca se han extraído y extraen minerales con interés económico tales como la wolframita, subproductos como la casiterita y la calcopirita, y en menor medida arsenopirita, pirita, marcasita, esfalerita (marmitita), siderita, dolomita, calcita, apatito, moscovita, turmalina, chorlo y clorita [1]. A pesar del aprovechamiento de los recursos de la mina, los restos de roca y minerales de diversas granulometrías conforman verdaderas montañas, sin darles uso alguno. Con la finalidad de aportar soluciones recicladoras, desde el año 2007 un grupo de investigadores de Universidad de Granada (España) y Universidad da Beira Interior (Portugal) trabajan conjuntamente para aprovechar estas enormes masas de material pétreo y lodos en recursos útiles desde el punto de vista económico, industrial y medioambiental, al amparo de las legislaciones vigentes sugeridas por la Unión Europea.

Este trabajo se centra en la obtención de materiales cerámicos y pastas para uso cerámico a partir de la utilización 


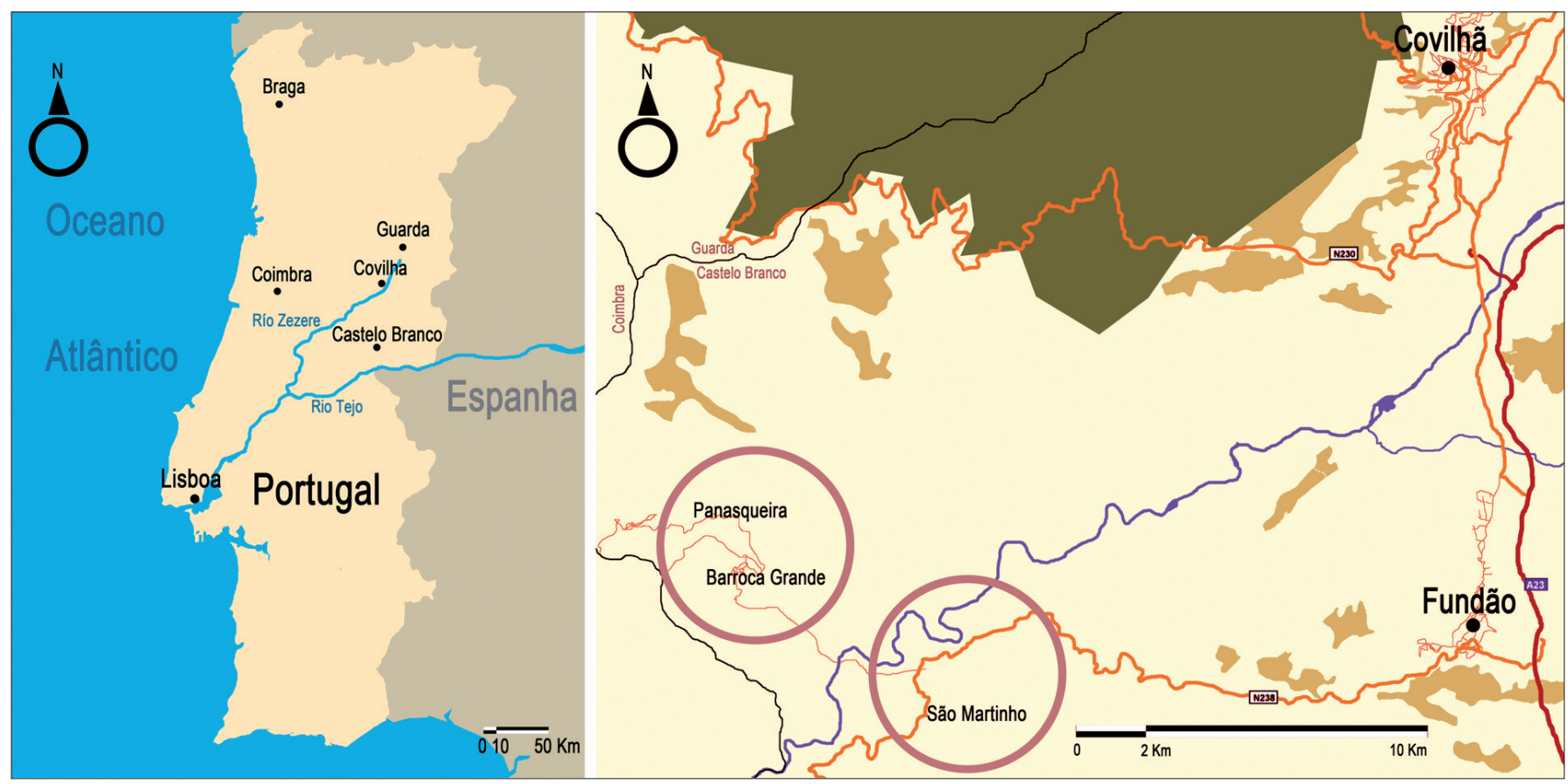

Figura 1. Situación geográfica de las minas de Panasqueira, próxima a Covilhã, región de Beira Interior, Portugal, de cuyas escombreras (Barroca Grande y São Martinho) procede el árido PAN para el conformado de nuevos materiales cerámicos.

de los citados residuos de minería de tungsteno, mejorando las características físicas y mecánicas, principalmente, respecto a las obtenidas en investigaciones previas [2-4]. Paralelamente se presentan los nuevos materiales cerámicos obtenidos con este procedimiento de reciclado y reutilización cuyos resultados son excelentes.

A nivel técnico los productos cerámicos obtenidos son interesantesen diversastemperaturas detrabajo, pues presentan buena compactación y, en su caso, vitrificación, especialmente a partir de $1100{ }^{\circ} \mathrm{C}$, donde los valores de resistencia mecánica son comparables a otros manufacturados cerámicos más "tradicionales". Este hecho es constatable, de igual forma, con los datos obtenidos mediante transmisión de pulsos ultrasónicos. Es reseñable a nivel mineralógico la tendencia hacia una simplificación composicional, a medida que se incrementa la temperatura de horneado $\left(1150{ }^{\circ} \mathrm{C}\right.$ a $\left.1300{ }^{\circ} \mathrm{C}\right)$, con presencia de neoformados del tipo mullita y hematite. De forma inversa, existe un aumento de porosidad-huecos y volumetría en las muestras cuando aumenta la temperatura, cuya morfología se hace progresivamente vacuolar, en el caso de la porosidad, hecho que condiciona una disminución de resistencia mecánica. Esta peculiaridad, en principio menos favorable, puede ser revertida, pues se plantea la utilización de estos neocerámicos con otros usos industriales (e. g. filtrado de fluidos, dispositivos para abrasión, etc.).

Existen importantes antecedentes que avalan esta labor recicladora, como los trabajos y estudios realizados por otros autores [5-16], conducente a la obtención de productos cerámicos a partir de la reutilización y reciclaje de materiales de desecho. Por ejemplo, Hevia et al. [8] propone la utilización de residuo de producción de una planta de fabricación de porcellanato (del $50 \%$ al $90 \%$ ) para formar nuevos productos cerámicos; Mera et al. [10], propone la reutilización del vidrio de desecho (entre el $42 \%$ y el $50 \%$ ) para preparar esmaltes porcelánicos; Arancibia et al. [13] la obtención de vidrio a partir de residuos de la minería del estaño (entre el $50 \%$ y el $65 \%$ de residuo) y Pappua et al. [15] presenta un estudio de la aplicación de residuos sólidos industriales y mineros, clasificándolos en función de su potencial de aplicación.

\section{PARTE EXPERIMENTAL}

Los materiales para obtener los nuevos productos cerámicos son mayoritariamente áridos de desecho de minería, procedente del área de Panasqueira en la región de Beira Interior, Portugal (figura 1). Estos residuos provienen de rocas y estratos minerales donde abundan los esquistos, grauvacas, cuarzos y pizarras, geocronológicamente ubicados en el Precámbrico Terminal [4]. Tras el proceso minero-extractivo e industrial los residuos son acumulados en enormes masas de material pétreo (figura 2) a los que no se les da uso concreto.

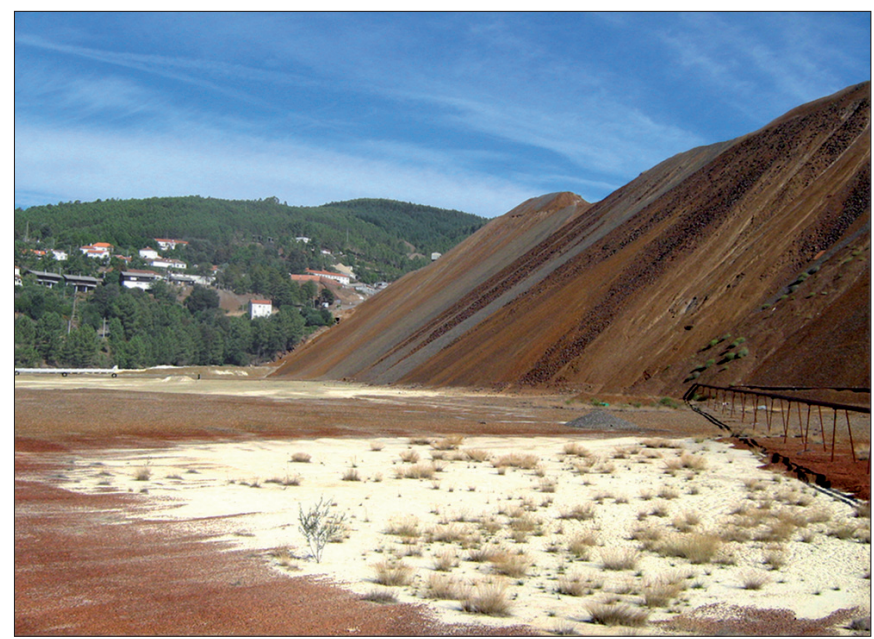

Figura 2. Escombreras de material pétreo de desecho procedente de las minas de Panasqueira (Barroca Grande), cerca de Covilhã en Portugal. 
Estos residuos en sus depósitos presentan una granulometría heterogénea que varía desde pocos milímetros hasta 3 ó 3,5 $\mathrm{cm}$. Se ha obviado la utilización de otros residuos procedentes de la actividad minera, clasificados con tamaños muy finos y forma de lamas por contener restos de metales pesados $(\mathrm{Cu}, \mathrm{Zn}, \mathrm{Mn}, \mathrm{As}$ y S), hecho que no descarta la presencia minoritaria de estos metales en los primeros.

También se ha utilizado caolín comercial (servido por Vícar S. A.) en el proceso de manipulado y conformado de los nuevos materiales cerámicos, que debido a su contenido de illita, junto a la caolinita, aporta al proceso plasticidad y compactibilidad durante el proceso de manufactura [14]. Este caolín comercial utilizado, que se distribuye como tal, no es puro, sino un producto industrial con alto contenido en caolinita y cuarzo conteniendo además otros elementos como la illita y clinocloro. Se ha utilizado agua potable, como vehículo plastificante, durante el proceso de aglomerado, preparación y amasado de las muestras frescas.

Los restos de minería han sido triturados, molidos y clasificados granulométricamente de forma previa al amasado de las muestras, utilizándose un molino de discos vibratorio Herzog, para trituración ultrafina (sin pérdidas de material pétreo). La calibración granulométrica se ha hecho con una tamizadora analítica Retsch AS 200 Digit que incluye una batería de cinco tamices de ocho pulgadas con el siguiente paso de luz: 0,5 mm, 0,425 mm, 0,3 mm, 0,2 $\mathrm{mm}$ y 0,1 $\mathrm{mm}$. El árido empleado para la compactación de muestras se ha seleccionado en una primera criba mediante tamizado con cedazo de luz de $0,6 \mathrm{~mm}$.

El material seleccionado procedente de residuos de minería se analizó mediante fluorescencia de rayos X (FRX), con un espectrómetro secuencial de longitud de onda dispersiva y generador de rayos X de $4 \mathrm{KW}$, marca Philips Magix Pro (PW-2440). Se prepararon tres muestras a partir de árido molido. La técnica ha sido la denominada "en perla sólida" por lo que hubieron de ser fundidas con tetraborato de litio para posterior irradiación con haz de rayos X. También se han caracterizado mineralógicamente diversas muestras de este estudio con difracción rayos X (DRX), utilizándose un difractómetro de polvo marca Bruker D8 Advance. Los datos se han interpretado con software "XPowder" y base de datos PDF2.DAT [17].

Las muestras estudiadas han sido las siguientes: cinco correspondientes al árido molido de Panasqueira, dos muestras de caolín comercial (Vícar S. A.) y dos muestras diferentes de material cerámico $(75 \%$ árido PAN $+25 \%$ de caolín comercial) por cada uno de los rangos térmicos de $800{ }^{\circ} \mathrm{C}, 900{ }^{\circ} \mathrm{C}, 1000{ }^{\circ} \mathrm{C}, 1100{ }^{\circ} \mathrm{C}, 1200{ }^{\circ} \mathrm{C}, 1250{ }^{\circ} \mathrm{C}$ y $1300{ }^{\circ} \mathrm{C}$ (en este último caso la proporción fue $50 \%$ árido PAN + $50 \%$ de caolín comercial). También se han analizado dos muestras cerámicas de cada una de las pastas comerciales utilizadas (de alfarero y pasta refractaria, de $\mathrm{SiO}_{2}$ ) en los rangos térmicos de $1000{ }^{\circ} \mathrm{C}$ y $1250{ }^{\circ} \mathrm{C}$, respectivamente.

La preparación de las probetas para el resto de ensayos comprende el mezclado en seco inicial del caolín y el árido, y posterior adición de agua de amasado; conformado de éstas en moldes desmontables de acero inoxidable con capacidad para seis probetas con forma de paralelepípedo recto y medidas normalizadas de $80 \mathrm{~mm} \times 20 \mathrm{~mm} \times 20 \mathrm{~mm}$. Se prepararon seis probetas por cada tipo de mezcla de árido de Panasqueira (PAN) al $10 \%, 15 \%, 25 \%$ y $50 \%$ de caolín, y por cada rango de cocción: $800{ }^{\circ} \mathrm{C}, 900{ }^{\circ} \mathrm{C}, 1000{ }^{\circ} \mathrm{C}, 1100{ }^{\circ} \mathrm{C}, 1200{ }^{\circ} \mathrm{C}$ y $1250{ }^{\circ} \mathrm{C}$ para todas las tipologías, y a $1300{ }^{\circ} \mathrm{C}$ sólo las mezclas al $50 \%$ de caolín, las únicas capaces de soportar esta temperatura sin fundir.

La cantidad de agua para amasado fue del $20 \%$ con las muestras al $10 \%, 15 \%$ y al $25 \%$, mientras que a las del $50 \%$ se les incorporó un $17 \%$ de agua en volumen, debido a que en esta mezcla se reduce la cantidad de árido y aumenta la cantidad de arcilla, cuyo menor tamaño de partícula facilita mejor adherencia de agua. Como elementos de referencia y estandarización se prepararon tres probetas de caolín puro por cada rango de cocción y doce probetas de pastas comerciales a su temperatura óptima de cocción (seis de pasta de alfarero a $1000{ }^{\circ} \mathrm{C}$ y seis de pasta refractaria a $1250{ }^{\circ} \mathrm{C}$ ), de $\mathrm{SiO}_{2}$.

Posteriormente al secado las probetas con las citadas mezclas fueron horneadas según el rango de temperatura establecido, en un horno marca Kittec Clasic Line CL-100/5 con temperatura máxima de $1320^{\circ} \mathrm{C}$. El ciclo de horneado se ha hecho incrementando la temperatura de $100{ }^{\circ} \mathrm{C} / \mathrm{h}$ hasta alcanzar la temperatura máxima definida, con meseta térmica de dos minutos y posterior enfriamiento en caída libre en cada grupo de muestras.

Todas las muestras fueron medidas con un calibre electrónico digital marca Amig (con una precisión de 0,01 $\mathrm{mm})$, previamente al horneado, tras secado a temperatura ambiente y tras el proceso de horneado. En cada probeta se tomaron ocho mediciones: dos en su dirección longitudinal y tres en cada una de sus dos direcciones transversales, para establecer la variación lineal y volumétrica. Así también, mediante el ensayo de pesada hidróstática (siguiendo las recomendaciones de la Norma Internacional ASTM C-20, se ha determinado la capacidad de absorción de agua (porosidad abierta).

Se ha calculado la velocidad de propagación de pulsos ultrasónicos en un total de setenta y cuatro muestras cerámicas para cualificar su madurez y concreción cerámica. Cinco mediciones ultrasónicas en catorce probetas de caolín industrial (dos en cada temperatura), igualmente en cinco probetas de pasta industrial refractaria (en la temperatura de $1250{ }^{\circ} \mathrm{C}$ ), al igual que cinco probetas de pasta roja de alfarero (en la temperatura de $1000{ }^{\circ} \mathrm{C}$ ). El resto, con cinco mediciones ultrasónicas por muestra, corresponden a dos probetas de material cerámico al $10 \%$, dos al $15 \%$ y dos al $25 \%$ de caolín, todas ellas en seis temperaturas $\left(800{ }^{\circ} \mathrm{C}, 900{ }^{\circ} \mathrm{C}, 1000{ }^{\circ} \mathrm{C}\right.$, $1100{ }^{\circ} \mathrm{C}, 1200{ }^{\circ} \mathrm{C}$ y $\left.1250{ }^{\circ} \mathrm{C}\right)$, y dos probetas de material cerámico al $50 \%$ de caolín en siete temperaturas $\left(800{ }^{\circ} \mathrm{C}\right.$, $900{ }^{\circ} \mathrm{C}, 1000{ }^{\circ} \mathrm{C}, 1100{ }^{\circ} \mathrm{C}, 1200{ }^{\circ} \mathrm{C}, 1250{ }^{\circ} \mathrm{C}$ y $\left.1300{ }^{\circ} \mathrm{C}\right)$.

Este ensayo no destructivo de materiales es una técnica habitual y extendida para el control de calidad y optimización en la producción de materiales cerámicos, como se puede encontrar entre diversos autores [18-22]. Se ha utilizado un emisor de pulsos ultrasónicos marca Tico Proceq, provisto de transductores a $54 \mathrm{kHz}$, intervalo de medición desde 15 a $6550 \mu \mathrm{s}$, resolución de 0,1 $\mu$ s, impulso de tensión de $1 \mathrm{kV}$, y tasa de impulso de $3 / \mathrm{s}$. En el ensayo se han seguido las recomendaciones de las Normas Internacionales ASTM E494 y ASTM C1175. Igualmente se han adaptado las recomendaciones de la Norma BS 1881-203 y la Norma Española UNE 83-308-86.

Se han estimado en las muestras cerámicas los valores de resistencia a flexión en tres puntos y resistencia a compresión uniaxial. En ambos casos se han utilizado cinco probetas para cada tipo de mezcla y sus correspondientes temperaturas y 
Tabla 1. AnÁlisis Químico elemental del ÁRido de PANASQueira PAN y del CaOlín (Vícar, S.A.).

\begin{tabular}{|c|c|c|c|c|c|c|c|c|c|c|c|c|}
\hline & $\begin{array}{l}\mathrm{SiO}_{2} \\
(\%)\end{array}$ & $\begin{array}{c}\mathrm{Al}_{2} \mathrm{O}_{3} \\
(\%)\end{array}$ & $\begin{array}{c}\mathrm{Fe}_{2} \mathrm{O}_{3} \\
(\%)\end{array}$ & $\begin{array}{c}\mathrm{MnO} \\
(\%)\end{array}$ & $\begin{array}{c}\mathrm{MgO} \\
(\%)\end{array}$ & $\begin{array}{l}\mathrm{CaO} \\
(\%)\end{array}$ & $\begin{array}{c}\mathrm{Na}_{2} \mathrm{O} \\
(\%)\end{array}$ & $\begin{array}{l}\mathrm{K}_{2} \mathrm{O} \\
(\%)\end{array}$ & $\begin{array}{c}\mathrm{TiO}_{2} \\
(\%)^{2}\end{array}$ & $\begin{array}{l}\mathrm{P}_{2} \mathrm{O}_{5} \\
(\%)\end{array}$ & $\begin{array}{c}\mathrm{Zr} \\
(\mathrm{ppm})\end{array}$ & $\begin{array}{l}\text { LOI } \\
(\%)\end{array}$ \\
\hline Caolín & $66,0-68,0$ & $20,0-21,0$ & $0,5-0,6$ & & 0,1 & 0,2 & 0,1 & $3,5-4$ & $0,2-0,4$ & & & $6,0-6,5$ \\
\hline PAN & 72,05 & 13,08 & 5,64 & 0,04 & 1,54 & 0,46 & 0,38 & 3,01 & 0,62 & 0,29 & 155,67 & 2,18 \\
\hline
\end{tabular}

TABla 2. ANÁlisis MiNERALÓGICO (DRX) DEL ÁRIDO PAN y DEL CAOLÍN (VíCAR S.A.) EMPLEAdOS.

\begin{tabular}{|c|c|c|c|c|c|c|c|c|c|c|}
\hline & $\begin{array}{c}\text { Caolinita } \\
(\%)\end{array}$ & $\begin{array}{c}\text { Cuarzo } \\
(\%)\end{array}$ & $\begin{array}{c}\text { Moscovita } \\
(\%)\end{array}$ & $\begin{array}{l}\text { Illita } \\
(\%)\end{array}$ & $\begin{array}{c}\text { Clinocloro } \\
(\%)\end{array}$ & $\begin{array}{c}\text { Microclina } \\
(\%)\end{array}$ & $\begin{array}{c}\text { Albita } \\
(\%)\end{array}$ & $\begin{array}{c}\text { Paragonita } \\
(\%)\end{array}$ & $\begin{array}{c}\text { Portlandita } \\
(\%)\end{array}$ & $\begin{array}{c}\text { Amorfos } \\
(\%)\end{array}$ \\
\hline Caolín & 31 & 41 & & 7 & & 13 & & & & 8 \\
\hline
\end{tabular}

cinco muestras de caolín industrial para todas las temperaturas ensayadas en este trabajo. También se han estudiado cinco muestras de pasta comercial de alfarero y pasta refractaria $\mathrm{SiO}_{2}$, horneadas a $1000{ }^{\circ} \mathrm{C}$ y $1250{ }^{\circ} \mathrm{C}$, respectivamente $(156$ probetas en total). El caso del ensayo de resistencia a flexión en tres puntos ha seguido las indicaciones de la Norma Internacional ASTM C 1161. En el de compresión uniaxial se han seguido las recomendaciones de la Norma Internacional ASTM C 773, utilizando las mitades resultantes del ensayo de resistencia a flexión en tres puntos, eliminando previamente el área irregular mediante corte con máquina de corte Struers, Accutom 2, con un disco de corte de diamante Struers M4D18 de $176 \mathrm{~mm} \times 0,8 \mathrm{~mm} \times 12,7 \mathrm{~mm}$.

En ambos ensayos se utilizó una máquina de ensayos mecánicos universal Zwick 1435, con una velocidad de $2 \mathrm{~mm} /$ min y carga máxima de $5 \mathrm{kN}$. Tanto el ensayo de resistencia a flexión en 3 puntos como el de compresión uniaxial resultan fundamentales a nivel industrial en la caracterización de material cerámico [23-27], así como en el control de calidad de materiales cerámicos ya sea en crudo $[28,29]$ o tras el horneado [30,31].

Parte de las muestras sometidas a esfuerzo mecánico han servido para hacer un estudio con microscopía electrónica de barrido (SEM), marca Hitachi, S-510 (tensión aceleración de $25 \mathrm{kV}$ ); detector de EDX (Röntec, M series, Edwin, Si-Li), y microanálisis (Edwin de Röntec). Algunos resultados se incluyen en el apartado correspondiente.

\section{RESULTADOS Y DISCUSIÓN}

En las tablas 1 y 2 se indican los resultados concernientes a los análisis químico y mineralógico del árido de Panasqueira (PAN) y del caolín. El análisis elemental obtenido mediante fluorescencia de rayos $X$ (FRX) del árido PAN y para el caolín (tabla 1), prevé un aceptable comportamiento frente a la temperatura de las nuevas pastas, debido a los altos contenidos en óxido de silicio $(\sim 72 \%$ en árido PAN y 66-68 \% en el caolín), al igual que óxido de aluminio ( 13\% en árido PAN y 20-21\% en caolín). Estos óxidos presentan gran resistencia térmica (temperatura de fusión de $1700{ }^{\circ} \mathrm{C}$ y $2000{ }^{\circ} \mathrm{C}$, respectivamente). No obstante, el árido PAN contiene proporciones considerables de elementos fusibles como el óxido de hierro $(5,6 \%)$ y el óxido de magnesio $(1,5 \%)$ que actuarán como inductores de fusión en la mezcla, junto con los elementos alcalinos, en particular el potasio $(3,01 \%)$. El caolín empleado incluye altos contenidos de elementos con propiedades refractarias, junto con elementos fundentes, con contenidos similares al árido PAN, particularmente de óxido de potasio (3-4\%).

Los análisis cuantitativos por difracción de rayos X (DRX), tabla 2, completan y aclaran a título orientativo lo inferido a partir del análisis elemental sobre los componentes refractarios y fundentes del caolín empleado. Se confirma la elevada presencia de minerales con aceptable refractariedad como el cuarzo (44\% aproximadamente) y otros como la caolinita y moscovita (illítica). En el caso de la moscovita, y también de la microclima, además de elementos refractarios ( $\mathrm{Si}$ y Al), contiene una buena proporción de fundente (potasio). En el caso del árido PAN, además de la abundante moscovita, contiene clinocloro, ambos componentes plásticos que aportan además de $\mathrm{Si}$ y Al, fundentes de hierro, magnesio y potasio. Además contiene albita, que es un feldespato sódico, y al igual que la paragonita aporta sodio a la mezcla. La portlandita identificada por DRX aporta calcio. En general la proporción de fundentes es muy elevada, tanto en el caolín empleado como el árido PAN. En particular, el potasio que debe proporcionar la presencia de fase líquida a temperaturas bajas.

El análisis mineralógico por DRX del caolín usado pone de manifiesto que el cuarzo supone algo menos de la mitad y la caolinita un tercio. Además, aparecen, otros minerales, como la illita y la microclina. En ambos casos aportan potasio como fundente para la mezcla. Algunos autores calculan el descenso del punto de fusión de las arcillas considerando las impurezas en forma de óxidos extraños, así el caolín utilizado podría bajar su temperatura de fusión casi $65^{\circ} \mathrm{C}$ [32]. Los contaminantes fundentes incluidos en el árido PAN podrían provocar descensos adicionales de casi $150^{\circ} \mathrm{C}$, todo ello sin considerar las posibles asociaciones eutécticas en la masa de las nuevas cerámicas.

El análisis composicional de los materiales cerámicos (nuevas pasta cerámicas y pastas cerámicas industriales) y su presencia porcentual aproximada se indican en la tabla 3. En la figura 3, se superponen los diagramas de difracción de rayos $\mathrm{X}$ de las mezclas de materiales cerámicos en las temperaturas de $800{ }^{\circ} \mathrm{C}, 900{ }^{\circ} \mathrm{C}, 1000{ }^{\circ} \mathrm{C}, 1100{ }^{\circ} \mathrm{C}, 1200{ }^{\circ} \mathrm{C}$, $1250{ }^{\circ} \mathrm{C}$ y $1300{ }^{\circ} \mathrm{C}$ (mezclas de $75 \%$ árido PAN y $25 \%$ caolín en todas las temperaturas, excepto en $1300{ }^{\circ} \mathrm{C}$ que corresponden al 50/50\%). Los picos de DRX se muestran con su intensidad absoluta para todas las muestras analizadas (una escala correspondiente a 200 cuentas por segundo se incluye en el caso de la muestra de $1300{ }^{\circ} \mathrm{C}$ ).

Cabe destacar la simplificación de compuestos cristalinos, a medida que aumenta la temperatura, con mayor presencia de fase vítrea. Igualmente la intensidad absoluta de los picos de DRX de cuarzo y moscovita decrece con el aumento 


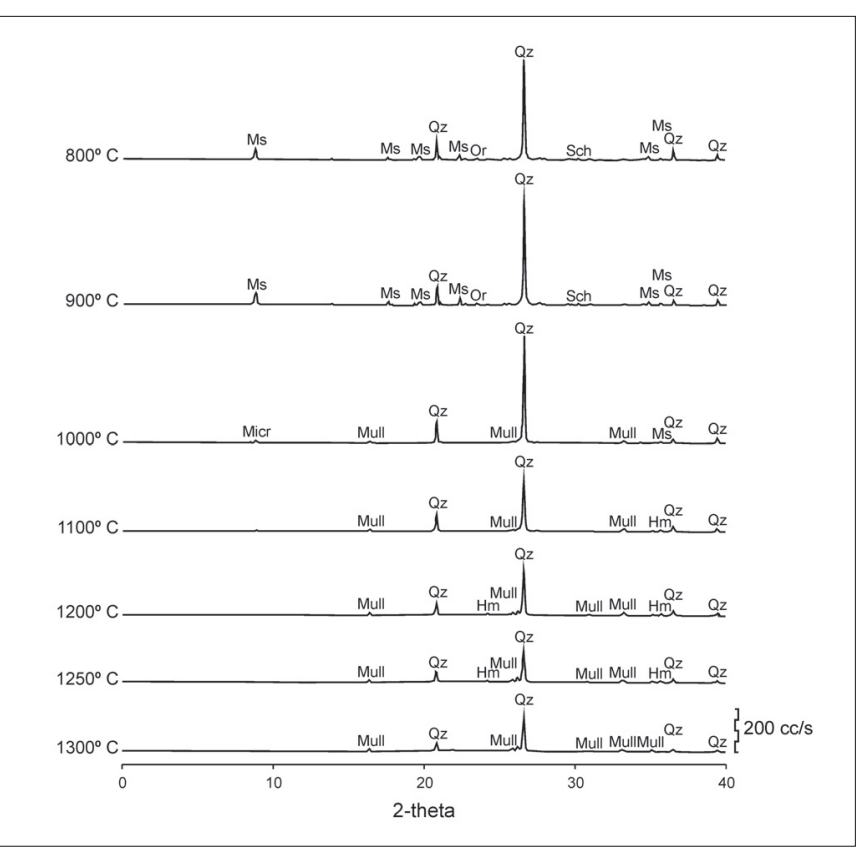

Figura 3. Diagramas de difracción de rayos $X$, de las nuevas pastas cerámicas a partir de residuos de minería de tungsteno en función de su temperatura de horneado (mezclas de $75 \%$ árido PAN y $25 \%$ caolín en todas las temperaturas, excepto en $1300^{\circ} \mathrm{C}$ que corresponden al 50/50\%). Donde: Qz - cuarzo; Mull - mullita; HM - hematite; Ms - moscovita; Micr - microclina; Sch - chorlo; Or - ortoclasa.

de temperatura, y en el caso de la moscovita desaparece totalmente a partir de los $1000{ }^{\circ} \mathrm{C}$. Aparece mullita, (figura $4 \mathrm{~A})$, junto con otros minerales neoformados ricos en óxido de hierro, visibles en forma de cristales de hematite (figura 4B) a partir de $1000-1100{ }^{\circ} \mathrm{C}$. Las pequeñas cantidades de microclina y ortoclasa que se observan en algunos casos se debe a su desigual presencia en las materias primas empleadas, que son ligeramente heterogéneas en lo que a su mineralogía y composición se refiere.

En tabla 4 se indican los valores de distribución granulométrica para el residuo de minería, tras la molienda y del caolín industrial. El árido PAN muestra la presencia de más de un tercio de fino-polvo, con diámetro inferior a $0,1 \mathrm{~mm}(34,2 \%)$. El resto, un $65 \%$ aproximadamente se distribuye de la siguiente manera: - partícula comprendida entre 0,1 y $0,2 \mathrm{~mm}(17,6 \%)$; entre 0,2 y $0,3 \mathrm{~mm}(9,7 \%)$; entre 0,3 y $0,425 \mathrm{~mm}(11,2 \%)$; entre 0,425 y $0,5 \mathrm{~mm}(10,8 \%)$ y entre 0,5 y 0,6 mm (16,4\%). El caolín, por su parte, presenta el $100 \%$ de partículas de polvo extrafino con tamaños inferiores, en todos los casos a 0,1 mm. Esta heterogeneidad de tamaños aporta a la mezcla cierta finura para el amasado de las nuevas pastas, semejante a la de pastas comerciales, permitiendo una adecuada cohesión entre sus diferentes componentes. Por otra parte, determinados tamaños de partícula actúan como verdaderos desengrasantes en la mezcla, inhibiendo la aparición de fisuras y grietas por contracción, antes y después del horneado.

En general la relación de absorción de agua (porosidad abierta) respecto a la variabilidad lineal (Tabla 5) de las muestras cerámicas es inversa: a temperaturas más bajas los porcentajes de absorción de agua son elevados (15-18\%), decreciendo a medida que se aumenta la temperatura de cocción. Ello se explica por la mayor sinterización de las muestras y aumento de fase líquida, generando desde $1200{ }^{\circ} \mathrm{C}$, una porosidad abierta de gran tamaño, lo que impide la retención del agua, por el contrario la variabilidad lineal de las muestras aumenta con el incremento de temperatura, consecuencia en mayor o menor medida de la aparición de fase líquida y burbujas.

TABLA 3. COMPUESTOS MINERALES Y SU CUANTIFICACIÓN APROXIMADA, PRESENTES EN LAS NUEVAS PASTAS CERÁMICAS DE RESIDUOS DE MINERÍA DE TUNGSTENO (PAN) Y DE DOS PASTAS COMERCIALES OBTENIDOS MEDIANTE DRX EN DIFERENTES TEMPERATURAS.

\begin{tabular}{|c|c|c|c|c|c|c|c|c|c|}
\hline & \multicolumn{7}{|c|}{ Nuevas pastas cerámicas (residuo minería, PAN + caolín) } & \multirow{3}{*}{$\begin{array}{c}\text { Pasta Roja } \\
1000^{\circ} \mathrm{C} \\
\end{array}$} & \multirow{3}{*}{$\begin{array}{c}\text { Pasta Refractari } \\
1260^{\circ} \mathrm{C} \\
\end{array}$} \\
\hline & \multirow{2}{*}{$\begin{array}{l}50 / 50 \% \\
1300{ }^{\circ} \mathrm{C}\end{array}$} & \multicolumn{6}{|c|}{$75 / 25 \%$} & & \\
\hline & & $1250^{\circ} \mathrm{C}$ & $1200^{\circ} \mathrm{C}$ & $1100{ }^{\circ} \mathrm{C}$ & $1000^{\circ} \mathrm{C}$ & $900{ }^{\circ} \mathrm{C}$ & $800^{\circ} \mathrm{C}$ & & \\
\hline Cuarzo & 33 & 33 & 40 & 48 & 39 & 52 & 51 & 50 & 13 \\
\hline Cristobalita & & & & & & & & & 10 \\
\hline Mullita & 47 & 39 & 35 & 31 & 16 & & & & 45 \\
\hline Hematite & & 8 & 9 & 8 & & & & & 6 \\
\hline Moscovita & & & & & 18 & 14 & 15 & & \\
\hline Microclina & & & & & 18 & & & & \\
\hline Chorlo & & & & & & 9 & 10 & & \\
\hline Ortoclasa & & & & & & 17 & 16 & & \\
\hline Illita & & & & & & & & 39 & \\
\hline Amorfos & 20 & 20 & 16 & 13 & 9 & 8 & 8 & 11 & 26 \\
\hline
\end{tabular}

TABLA 4. ANÁLISIS GRANULOMÉTRICO PORCENTUAL DEL ÁRIDO PAN, TRAS MOLTURACIÓN Y DEL CAOLÍN EMPLEADO EN LA REALIZACIÓN DE LAS PASTAS (DATOS CAOLÍN APORTADOS POR FABRICANTE Ví́CAR, S.A.).

\begin{tabular}{|c|c|c|c|c|c|c|c|c|c|c|c|}
\hline & \multicolumn{11}{|c|}{ Tamaño de partícula $(\mu \mathrm{m})$} \\
\hline & $600-500$ & $500-425$ & $425-300$ & $300-200$ & $200-100$ & $<100$ & $<40$ & $<10$ & $<5$ & $<2$ & $<0,5$ \\
\hline Caolín & & & & & & 0,25 & 0,35 & 40,5 & 29,8 & 19,1 & 8,3 \\
\hline PAN & 16,4 & 10,8 & 11,2 & 9,7 & 17,6 & 34,2 & & & & & \\
\hline
\end{tabular}



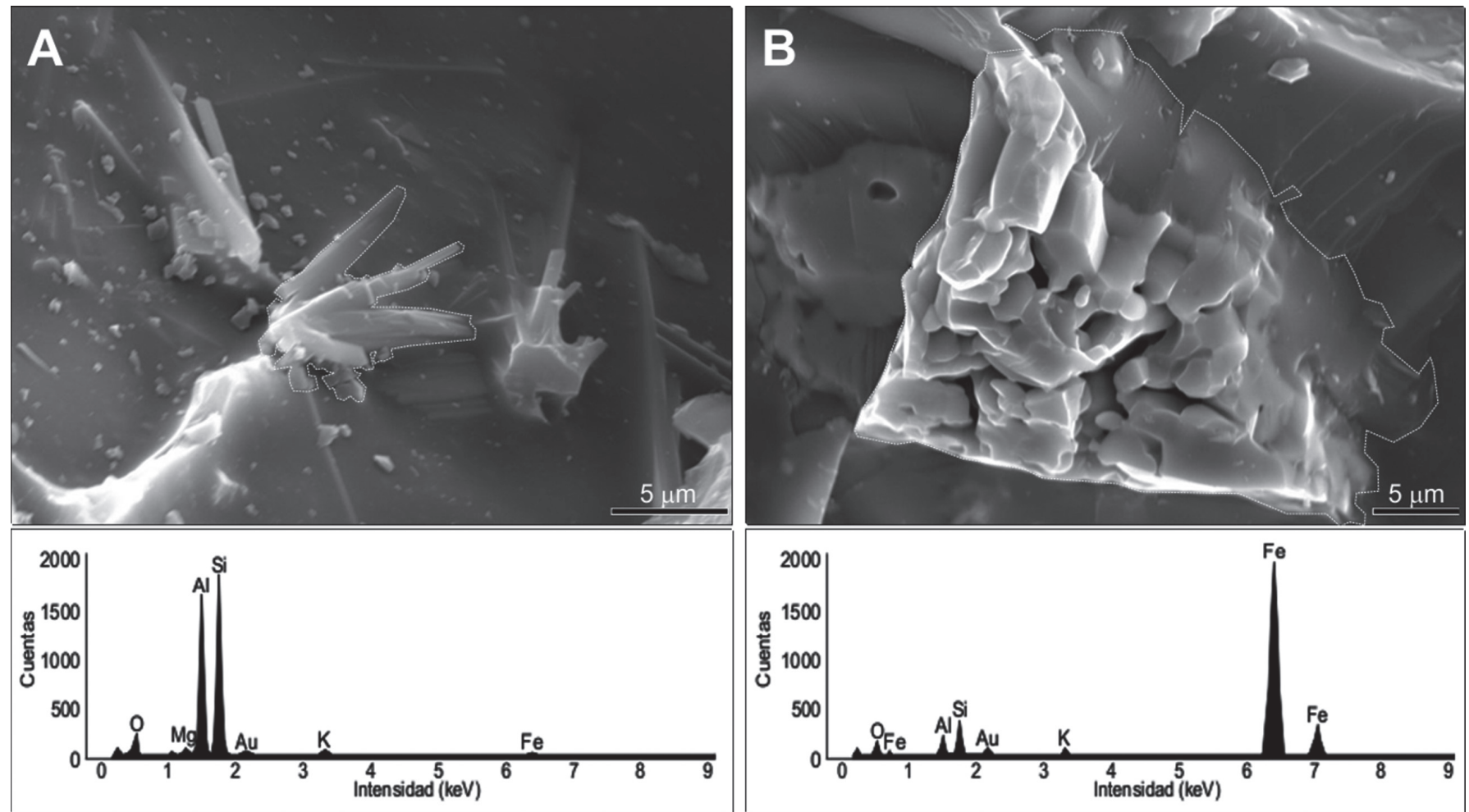

Figura 4. Imágenes de microscopía electrónica de barrido en muestras cerámicas basadas en residuos de minería de tungsteno: A) Crecimiento de cristales neoformados cuya composición y morfología se corresponde con mullita en nuevas pastas cerámicas (75 \% árido PAN y $25 \%$ caolín) a temperatura de $1200{ }^{\circ} \mathrm{C}(4000 x)$; B) Crecimiento de cristales neoformados cuya composición y morfología se corresponde con hematite en nuevas pastas cerámicas $\left(75 \%\right.$ árido PAN y $25 \%$ caolín) a temperatura de $1250^{\circ} \mathrm{C}(3000 x)$. Con línea difusa de color blanco se han resaltado sendas cristalizaciones. Se incluyen diagramas de dispersión de energía por rayos X (EDX) correspondiente a cada neoformado.

TABLA 5. VARIABILIDAD LINEAL $\left(\Delta_{\mathrm{L}}\right)$ Y ABSORCión DE AGUA (AA) PORCENTUALES DE MUESTRAS CERÁMiCAS A PARTIR DE MEZCLAS DE RESIDUOS DE MiNERÍA (PAN) Y ADICIONES DE CAOLÍN AL 10, 15, 25 Y $50 \%$

\begin{tabular}{|c|c|c|c|c|c|c|c|c|}
\hline \multirow{3}{*}{$\begin{array}{l}\mathrm{T}\left({ }^{\circ} \mathrm{C}\right) \\
\mathrm{T}\left({ }^{\circ} \mathrm{C}\right)\end{array}$} & \multicolumn{8}{|c|}{ Nuevas pastas cerámicas (PAN + caolín) } \\
\hline & \multicolumn{2}{|c|}{$\begin{array}{c}\text { Mezcla } \\
90+10 \%\end{array}$} & \multicolumn{2}{|c|}{$\begin{array}{c}\text { Mezcla } \\
85+15 \%\end{array}$} & \multicolumn{2}{|c|}{$\begin{array}{c}\text { Mezcla } \\
75+25 \%\end{array}$} & \multicolumn{2}{|c|}{$\begin{array}{c}\text { Mezcla } \\
50+50 \%\end{array}$} \\
\hline & $\Delta_{\mathrm{L}}$ & AA & $\Delta_{\mathrm{L}}$ & AA & $\Delta_{\mathrm{L}}$ & AA & $\Delta_{\mathrm{L}}$ & AA \\
\hline 800 & 0,98 & 14,684 & 0,56 & 15,084 & 0,86 & 16,185 & 0,77 & 17,793 \\
\hline 900 & 0,99 & 15,174 & 0,79 & 16,241 & 1,05 & 17,578 & 0,91 & 18,047 \\
\hline 1000 & 0,94 & 13,910 & 0,60 & 14,027 & 0,72 & 15,314 & 0,56 & 15,295 \\
\hline 1100 & $-1,76$ & 6,940 & $-2,12$ & 7,464 & $-2,17$ & 7,634 & $-2,49$ & 8,428 \\
\hline 1200 & 6,94 & 1,960 & 3,42 & 1,591 & 1,26 & 1,367 & $-3,25$ & 1,592 \\
\hline 1250 & 24,81 & 2,744 & 22,23 & 2,936 & 18,01 & 1,689 & 4,05 & 1,143 \\
\hline 1300 & & & & & & & 4,35 & 0,748 \\
\hline
\end{tabular}

Con respecto a la variabilidad volumétrica tras el horneado de las nuevas pastas (figura 5), hay que señalar que se produce una expansión muy pequeña hasta los $1000^{\circ} \mathrm{C}$ (aproximada al $2 \%)$, con valores muy homogéneos entre las diferentes pastas (todas las pastas PAN y el caolín expanden mínimamente, mientras que la pasta roja comercial contrae mínimamente), sin grandes diferencias entre los valores mínimo y máximo $\left(1,68 \%\right.$ en las muestras al $15 \%$ a $800{ }^{\circ} \mathrm{C}$ frente a un $3,19 \%$ en las muestras al $25 \%$ a $900{ }^{\circ} \mathrm{C}$ ). Los valores de expansión volumétrica son razonables en mezclas con alto contenido en cuarzo, pero sobre todo por minerales feldespáticos. En este sentido, según Winkler [33], la expansión volumétrica de albita y ortosa se sitúa en porcentajes análogos (1-3\%) a los observados en nuestras muestras cerámicas y las muestras confeccionadas con caolín industrial, desde $800{ }^{\circ} \mathrm{C}$ a $1000{ }^{\circ} \mathrm{C}$. El cuarzo contenido en las mezclas también varía volumétricamente desde los $500^{\circ} \mathrm{C}$ en adelante (transición de cuarzo $\alpha$ a $\beta$ ), aunque este polimorfo es reversible hasta aproximadamente $1050^{\circ} \mathrm{C}$, por lo que su incidencia en la variación volumétrica positiva es dudosa.

La temperatura de $1100{ }^{\circ} \mathrm{C}$ marca una contracción generalizada de las muestras, también bastante homogénea, si bien a mayor porcentaje de caolín, mayor es la contracción $(5,18 \%$ en las muestras al $10 \%$ de caolín frente al 7,30 \% en las muestras al $50 \%$ de caolín). A $1200{ }^{\circ} \mathrm{C}$, por su parte, comienza una heterogeneidad manifiesta, que aumentará conforme a la subida de la temperatura. A mayor porcentaje de caolín, menor es la expansión de las muestras. Las muestras al $50 \%$ 


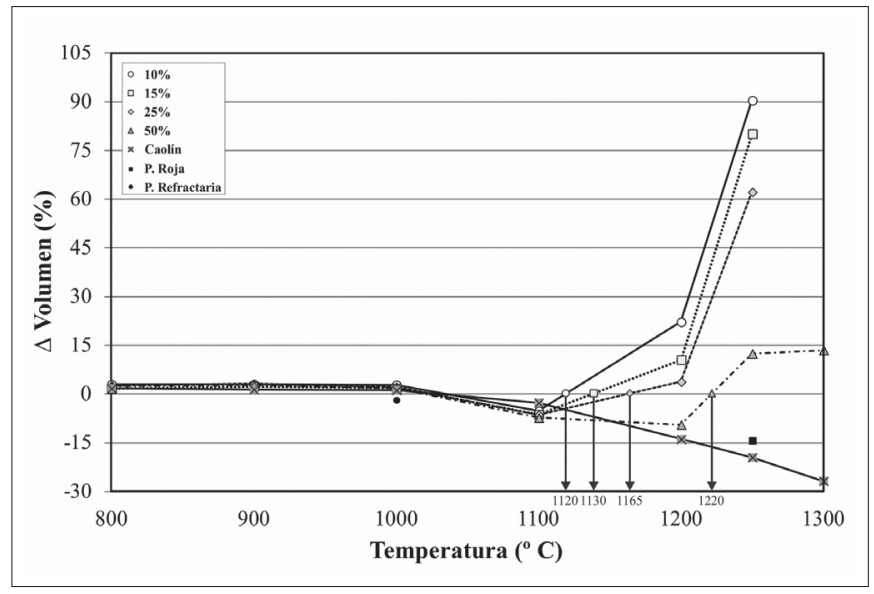

Figura 5. Variación volumétrica porcentual en función de la temperatura de las mezclas cerámicas PAN con 10, 15, 25 y $50 \%$ de caolín, caolín comercial y dos pastas comerciales (roja y refractaria). Las flechas indican la temperatura donde cada mezcla PAN experimentaría, en teoría, variabilidad nula.

disminuyen su volumen un $9,44 \%$, mientras que el resto de muestras expanden. Las muestras al $25 \%$ de caolín lo hacen de manera muy moderada $(3,79 \%)$, mientras que la expansión aumenta considerablemente en las muestras cerámicas al $15 \%$ de caolín $(10,56 \%)$ y al $10 \%$ de caolín $(22,22 \%)$. A $1250{ }^{\circ} \mathrm{C}$ se produce un aumento considerable de volumen en las pastas PAN, con valores que oscilan entre el $12,52 \%$ de las muestras al $50 \%$ de caolín, frente al elevado 90,41\% de las muestras al $10 \%$. Por el contrario, tanto el caolín como la pasta refractaria comercial contraen, $19,47 \%$ y $14,26 \%$, respectivamente.

A $1300{ }^{\circ} \mathrm{C}$, las muestras cerámicas al $50 \%$ de caolín, las únicas que soportan esta temperatura sin fundir, aumentan su volumen en un 13,55\%, mientras que el caolín contrae un $26,79 \%$. El hecho, que hace que las mezclas y el propio caolín contraigan desde el rango térmico de $1100{ }^{\circ} \mathrm{C}$, está motivado por el inicio de fusión de materiales, con aproximación de partículas arcillosas. A partir de $1200{ }^{\circ} \mathrm{C}$ las muestras cerámicas con menor proporción de caolín experimentan deformaciones (aumento de volumen) por el exceso de fusión y presencia de fase líquida, considerablemente menor en la mezcla al $50 \%$, en cuyo rango se observa todavía contracción. El caolín sin embargo contrae hasta una cuarta parte de su volumen total a la máxima temperatura $\left(1300^{\circ} \mathrm{C}\right)$.

Esta heterogeneidad en cuanto a la variabilidad volumétrica de las nuevas pastas cerámicas, consecuencia de su composición química, posibilita la obtención de productos manufacturados neocerámicos que no experimenten cambios significativos en su forma; para ello, con una mayor precisión en la temperatura de horneado de las mezclas al $10 \%\left(1120^{\circ} \mathrm{C}\right), 15 \%\left(1130{ }^{\circ} \mathrm{C}\right)$, $25 \%\left(1165{ }^{\circ} \mathrm{C}\right)$ y $50 \%$ de caolín $\left(1220^{\circ} \mathrm{C}\right)$, estimamos que las variaciones serían nulas o insignificantes (figura 5).

En la tabla 6 se indican los datos promedio del velocidad de pulsos ultrasónicos en función de la temperatura. En primer lugar señalar el comportamiento homogéneo de los cuatro tipos de pastas que experimentan incrementos análogos hasta los $1200{ }^{\circ} \mathrm{C}$, con valores finales ligeramente diferentes. Esta diferencia aumenta a $1250{ }^{\circ} \mathrm{C}$. Los valores comprendidos entre $800{ }^{\circ} \mathrm{C}$ y $1000{ }^{\circ} \mathrm{C}$ son bajos en las nuevas cerámicas y el caolín, propios de pastas porosas subcocidas, que no han adquirido madurez (oscilan entre $630 \mathrm{~m} / \mathrm{s}$ en mezclas al $15 \%$ a $800{ }^{\circ} \mathrm{C}$, hasta $1790 \mathrm{~m} / \mathrm{s}$ en las mezclas al $10 \%$ a horneado de $1000{ }^{\circ} \mathrm{C}$ ). Ello es significativo al comparar sus valores con los de la pasta roja comercial $(3110 \mathrm{~m} / \mathrm{s}$ para una temperatura de cocción de $1000{ }^{\circ} \mathrm{C}$ ). Las nuevas muestras cerámicas (PAN) consiguen valores próximos a la pasta roja comercial cuando se someten a $1100{ }^{\circ} \mathrm{C}(2930 \mathrm{~m} / \mathrm{s}$ de las mezclas al $10 \%$ y $3040 \mathrm{~m} / \mathrm{s}$ para mezclas al $25 \%$ de caolín), temperatura a la que empiezan a desarrollar cierta vitrificación.

Los valores de trasmisión de pulsos ultrasónicos aumentan considerablemente a la temperatura de $1200{ }^{\circ} \mathrm{C}(3515 \mathrm{~m} / \mathrm{s}$ de las mezclas al $10 \%$ y $3820 \mathrm{~m} / \mathrm{s}$ las del $50 \%$ de caolín), superando los valores de la pasta roja comercial y situándose en valores análogos y superiores (mezcla al $50 \%$ ) a la pasta refractaria comercial que consigue $3693 \mathrm{~m} / \mathrm{s}$. En el caso del caolín no se desarrollan velocidades elevadas hasta los $1200{ }^{\circ} \mathrm{C}$ (3255 m/s), aumentado progresivamente hasta los $1300{ }^{\circ} \mathrm{C}$ (4325 m/s), con un buen nivel de vitrificación y compactación. La mezcla al $50 \%$ de caolín, obtiene los mejores valores en altas temperaturas, al contrario que las mezclas al $10 \%, 15 \%$ y $25 \%$ de caolín en $1250{ }^{\circ} \mathrm{C}$, con descensos en la velocidad de pulsos ultrasónicos, respecto a $1200{ }^{\circ} \mathrm{C}$, debido al aumento de porosidad en estas muestras. En el caso de la mezcla al $50 \%$ de caolín, tanto a $1250{ }^{\circ} \mathrm{C}$, como $1300{ }^{\circ} \mathrm{C}$, existe aumento de porosidad, si bien es cierto que la mayor presencia de caolín proporciona una matriz más sólida y compactada.

En figura 6 se indican la evolución gráfica del módulo de ruptura a carga máxima de las diferentes muestras a flexión en 3 puntos y resistencia a compresión. Para el ensayo de flexión, as pastas horneadas a $800{ }^{\circ} \mathrm{C}, 900^{\circ} \mathrm{C}$ y $1000{ }^{\circ} \mathrm{C}$, presentan unas resistencias muy bajas (similares entre todos los primeros rangos), siendo a partir de $1100{ }^{\circ} \mathrm{C}$ cuando aumentan, mostrando diferencias según la composición de la muestra. Los valores de desviación estándar son aceptables, la desviación máxima es en la mayoría de las pruebas menor al $10 \%$. Como ejemplos de esta excepción se indican muestras

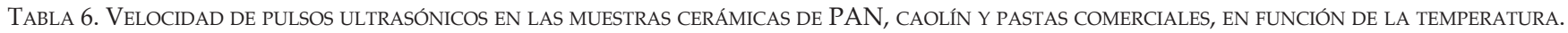

\begin{tabular}{|c|c|c|c|c|c|c|c|}
\hline \multirow[b]{2}{*}{$\mathrm{T}\left({ }^{\circ} \mathrm{C}\right)$} & \multicolumn{4}{|c|}{ Nuevas pastas cerámicas (PAN + caolín) } & \multirow[b]{2}{*}{ Caolín } & \multirow{2}{*}{$\begin{array}{l}\text { Pasta } \\
\text { Roja }\end{array}$} & \multirow{2}{*}{$\begin{array}{c}\text { Pasta } \\
\text { Refractaria }\end{array}$} \\
\hline & $\begin{array}{c}\text { Mezcla } \\
90+10 \%\end{array}$ & $\begin{array}{c}\text { Mezcla } \\
85+15 \%\end{array}$ & $\begin{array}{c}\text { Mezcla } \\
75+25 \%\end{array}$ & $\begin{array}{c}\text { Mezcla } \\
50+50 \%\end{array}$ & & & \\
\hline 800 & 650 & 630 & 665 & 720 & 1015 & & \\
\hline 900 & 785 & 775 & 755 & 795 & 1120 & & \\
\hline 1000 & 1790 & 1720 & 1735 & 1490 & 1155 & 3110 & \\
\hline 1100 & 2930 & 3010 & 3040 & 2940 & 1705 & & \\
\hline 1200 & 3515 & 3560 & 3665 & 3820 & 3255 & & \\
\hline 1250 & 3310 & 3290 & 3595 & 3860 & 3875 & & 3693 \\
\hline 1300 & & & & 3950 & 4325 & & \\
\hline
\end{tabular}




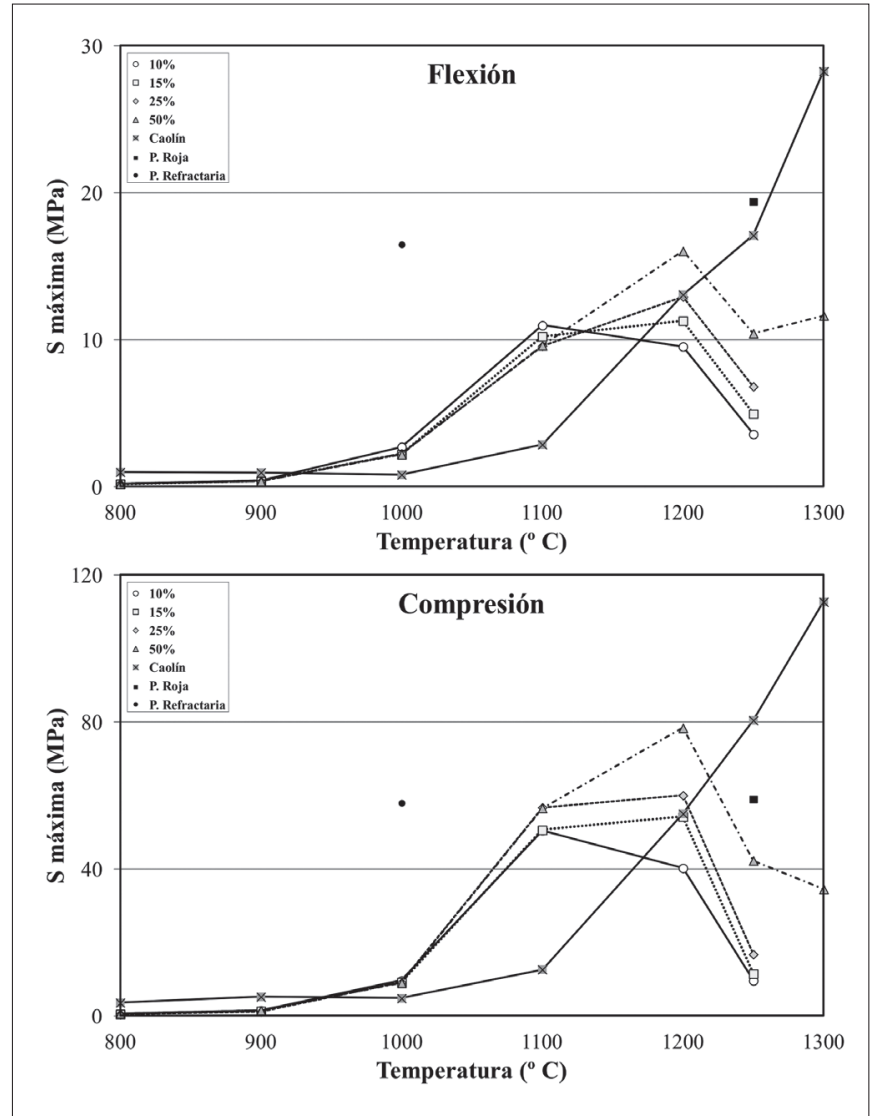

Figura 6. Evolución del módulo de ruptura en flexión y compresión de las muestras cerámicas PAN con 10, 15, 25 y $50 \%$ de caolín, caolín comercial y dos pastas comerciales (roja y refractaria), en función de la temperatura.

de cerámicas PAN, con árido de minería al $85 \%$ y $15 \%$ de caolín, a $1250{ }^{\circ} \mathrm{C}$, con un rango de error del $17 \%$; la muestra con árido de minería al $75 \%$ y $25 \%$ de caolín, a $1100{ }^{\circ} \mathrm{C}$ y $1250{ }^{\circ} \mathrm{C}$, respectivamente, indican una variación del $20 \%$. Las muestras de caolín a $1250{ }^{\circ} \mathrm{C}$ presentan una desviación máxima del $32 \%$.

A bajas temperaturas, no se produce una correcta "maduración" de las pastas, existiendo poca vitrificación que aporte cohesión. De igual manera ocurre en la probeta a base de caolín, donde su resistencia a flexión se incrementa a mayor temperatura (28 $\mathrm{MPa}$ a $\left.1300{ }^{\circ} \mathrm{C}\right)$. A $1100{ }^{\circ} \mathrm{C}$ las resistencias de las nuevas pastas aumentan, superando los valores del caolín en la misma temperatura $(2,9 \mathrm{MPa})$. A $1100{ }^{\circ} \mathrm{C}$, el valor más elevado corresponde con la proporción al $10 \%$ de caolín (11 $\mathrm{MPa})$. Por el contrario, en otras proporciones de caolín (15\%, $25 \%$ y $50 \%$ ), el valor máximo se da en $1200{ }^{\circ} \mathrm{C}$, con valores de resistencia más elevados cuanto mayor es su porcentaje de caolín (desde 9,5 hasta $13 \mathrm{MPa}$ ).

La mezcla al $50 \%$ PAN y $50 \%$ caolín tiene su mejor valor a $1200{ }^{\circ} \mathrm{C}$, consecuencia de una buena proporcionalidad ente compuestos refractarios y fundentes, generando una buena fase vítrea en las muestras, bastante evidente en las imágenes de SEM (figura 7). Sin desmesurada presencia de burbujas y vacuolas que resten resistencia mecánica, pues la porosidad ejerce un efecto reductor sustancial en la mayoría de las propiedades mecánicas de los materiales cerámicos, y concretamente en la resistencia mecánica a la flexión, en el módulo de Young y en la energía de fractura, considerando

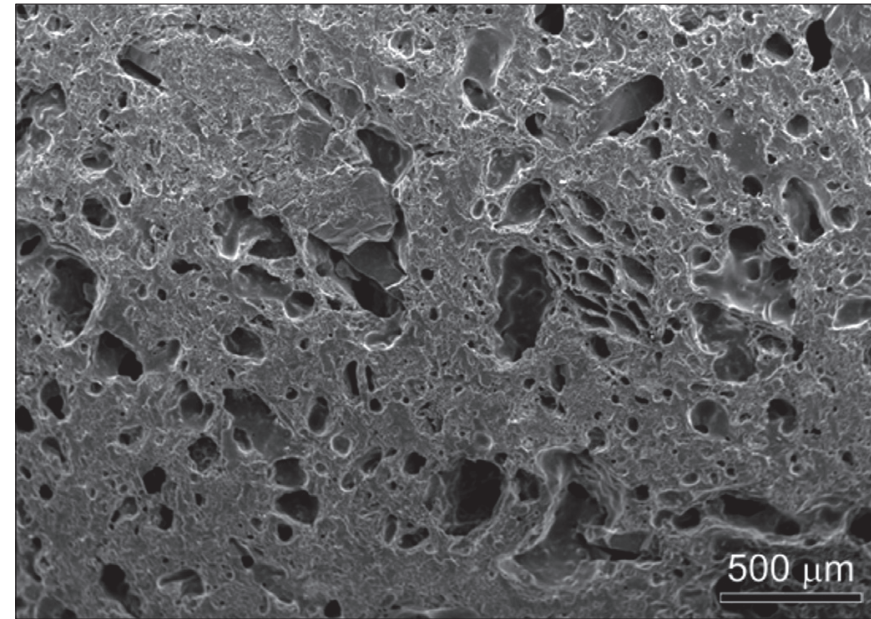

Figura 7. Imagen de microscopía electrónica de barrido en muestra cerámica de $50 \%$ PAN y $50 \%$ caolín a temperatura de $1200{ }^{\circ} \mathrm{C}$ (ampliación de 40x).

los poros como puntos de concentración de tensiones que facilitan la fractura del material [34].

A partir $1250{ }^{\circ} \mathrm{C}$ los valores de resistencia a flexión decrecen en todas las pastas a base de residuos de minería, con la tendencia anterior: valores más elevados cuanto mayor porcentaje de caolín contienen las mezclas. A $1300{ }^{\circ} \mathrm{C}$, la pasta PAN/caolín al 50/50 \%, la única que soporta esta temperatura sin fundir, aumenta ligeramente su resistencia con respecto a su valor a $1250{ }^{\circ} \mathrm{C}(11,6 \mathrm{MPa}$ frente a $10,4 \mathrm{MPa})$.

Las pastas comerciales, elaboradas industrialmente, obtienen valores superiores de resistencia a flexión, en rangos térmicos inferiores, que las obtenidas con residuos de minería. De esta forma la pasta roja comercial obtiene a $1000{ }^{\circ} \mathrm{C}$ valores de $16,5 \mathrm{MPa}$, superiores a las pastas elaboradas por nosotros. Valores análogos en nuestras pastas se obtienen a $1200{ }^{\circ} \mathrm{C}$ (PAN/caolín al 85/15\%: 11,3 MPa; 75/25\%: 12,9 MPa, y 50/50\%: $16 \mathrm{MPa}$ ). La pasta refractaria comercial a $1250{ }^{\circ} \mathrm{C}$, consigue una resistencia bastante superior $(19,4 \mathrm{MPa})$, mientras las mezclas PAN con la misma esta temperatura $(50 / 50 \%$, a $1200{ }^{\circ} \mathrm{C}$, obtiene $16 \mathrm{MPa}$ ).

En el caso del ensayo de resistencia a compresión uniaxial la evolución de los resultados obtenidos entre las diferentes muestras son análogos y permiten la validación respecto al ensayo de flexión. Los valores máximos en el caso de resistencia a compresión difieren dos órdenes de magnitud, en relación a los de flexión. Las resistencias obtenidas de las muestras horneadas a $800{ }^{\circ} \mathrm{C}$ y $900{ }^{\circ} \mathrm{C}$ son muy bajas y similares entre sí en todos los tipos de muestras. En el caso de $1000^{\circ} \mathrm{C}$ las resistencias son ligeramente más elevadas (entre 9,7 MPa en la mezcla PAN/caolín al 10/90 \% y 9 MPa al 50/50 \%). El caolín no presenta resistencias elevadas altas hasta los $1200{ }^{\circ} \mathrm{C}$.

A partir de los $1100{ }^{\circ} \mathrm{C}$ comienzan a desarrollar resistencias más altas, bastante más elevadas que el caolín puro a esta temperatura. Además se produce una diferencia con la tendencia observada en el ensayo de flexión. En éste, a $1100{ }^{\circ} \mathrm{C}$, mostraban mayor resistencia las muestras con menor caolín (10 \% y $15 \%$ ), mientras que en el ensayo de compresión uniaxial la mejor resistencia se alcanza con más caolín (25\% y $50 \%$ ), aunque los valores son muy próximos (51 MPa al PAN/ caolín $10 / 90 \%$ y $57 \mathrm{MPa}$ al $25 / 75 \%$ ).

A $1200{ }^{\circ} \mathrm{C}$ las pastas al $15 \%, 25 \%$ y $50 \%$ de caolín alcanzan sus mejores valores, con 54, 60 y $78 \mathrm{MPa}$, respectivamente. 
Estos datos son fundamentales al establecer una comparación con las pastas comerciales, ya que todos los tipos de mezcla, horneadas a $1100{ }^{\circ} \mathrm{C}$, obtienen valores próximos a las pastas comerciales en su temperatura óptima ( $58 \mathrm{MPa}$ de la pasta roja a $1000{ }^{\circ} \mathrm{C}$ y $59 \mathrm{MPa}$ de la pasta refractaria a $1250{ }^{\circ} \mathrm{C}$ ). En todo caso a $1200{ }^{\circ} \mathrm{C}$, tanto las muestras al $25 / 75 \%$ como, sobre todo, las muestras al $50 / 50 \%$, superan dichas máximas. El valor medio de $78 \mathrm{MPa}$ de la pasta al $50 \%$ de caolín es el resultado más elevado de todas las cerámicas PAN (con residuos de minería de tungsteno), superando ampliamente los valores de las pastas comerciales y sólo superado por los valores del caolín puro sometido a $1250{ }^{\circ} \mathrm{C}(80 \mathrm{MPa})$ y a $1300{ }^{\circ} \mathrm{C}(113 \mathrm{MPa})$.

A temperatura de $1250{ }^{\circ} \mathrm{C}$, las resistencias máximas de las nuevas cerámicas decrecen debido al aumento considerable de volumen. En esta temperatura, límite para las muestras al $10 \%, 15 \%$ y $25 \%$ de caolín, existe mayor heterogeneidad de los valores, obteniendo mejores resultados cuanto mayor es el porcentaje de caolín. Las muestras al $50 \%$ a $1300{ }^{\circ} \mathrm{C}$ también decrecen su valor (35 MPa), no obstante, tanto a $1300{ }^{\circ} \mathrm{C}$ como a $1250{ }^{\circ} \mathrm{C}$ los valores obtenidos por las pastas con proporciones de PAN/caolín al 50/50\%, son bastante considerables teniendo en cuenta la gran porosidad de las mismas. El caolín por su parte alcanza a esta temperatura su mejor valor, debido a su mayor vitrificación, aunque debe considerarse su excesiva contracción volumétrica. A diferencia del ensayo de flexión, donde las pastas comerciales obtenían valores ligeramente superiores a los mejores valores de nuestras muestras, en el ensayo de compresión uniaxial puede observarse que las pastas a partir de residuos de minería son equiparables a las comerciales y, en algunos casos las superan (mezcla al $50 \%$ de caolín a $1200{ }^{\circ} \mathrm{C}$ ).

\section{CONCLUSIONES}

Los nuevos materiales cerámicos presentados, con una importante base de residuos de minería de Tungsteno, pueden conllevar un alto grado de aprovechamiento en diferentes sectores de la economía, a la par que forman parte de la actividad de reciclado y sostenibilidad medioambiental.

Técnicamente estos nuevos materiales cerámicos pueden competir sin complejos con otros disponibles en el mercado, pues parten de materias primas ricas en componentes silicatados de óptima refractariedad. La cocción a diferentes temperaturas de los restos de minería (PAN) y el aglutinante a base de caolín, en diferentes proporciones (PAN/caolín al $90 / 10 \%$ hasta $50 / 50 \%$ ) al producir fases neoformadas de alta temperatura, en particular mullita, aporta calidad a los materiales cerámicos obtenidos. Podemos afirmar, no obstante, que es posible obtener materiales cerámicos con la única presencia de residuos de minería de tungsteno, sin aportación de caolín, pues la composición química de estos residuos incluye óxidos de tipo ácido, óxidos neutros y óxidos básicos.

Más aún, con mejoras técnicas, es factible la obtención de neoformados de mullita en este tipo de materiales cerámicos, sin incorporación de minerales de la arcilla. Otros ajustes en la reología de las mezclas, granulometría, incorporación de agua de amasado, ajuste del procedimiento de homogeneización y fijación de curvas térmicas, producirán materiales cerámicos muy útiles desde el punto de vista comercial.
Los manufacturados cerámicos aquí presentados tienen buenas propiedades técnicas en general, así como aplicaciones en ingeniería civil, rehabilitación patrimonial, usos artísticos, etc., desde temperaturas de cocción de $1000{ }^{\circ} \mathrm{C}$ hasta $1250{ }^{\circ} \mathrm{C}$, e incluso $1300^{\circ} \mathrm{C}$. Puede resultar de utilidad el ajuste de la temperatura de horneado, según cada mezcla, para evitar o minimizar los cambios volumétricos en los productos manufacturados: $1120^{\circ} \mathrm{C}$, en mezclas PAN/caolín al 10/90 \%; $1130{ }^{\circ} \mathrm{C}$, al $85 / 15 \% ; 1165{ }^{\circ} \mathrm{C}$, al $75 / 25 \%$ y $1220^{\circ} \mathrm{C}$ con mezclas al $50 / 50 \%$, todo ello sin disminuciones sustanciales de resistencia mecánica de los productos cerámicos obtenidos.

A nivel mecánico este tipo de manufacturados son más resistentes a esfuerzos de compresión que a flexión, en perfecta concordancia con estudios previos, ya que en los materiales rígidos como los cerámicos, sometidos a cargas de compresión las grietas incipientes tienden a cerrarse, mientras que ante cargas de tracción las grietas tienden a abrirse dando lugar a la fisuras y fracturas frágiles. Menos útiles, o con utilidades menos tradicionales, pueden resultar los materiales cerámicos obtenidos entre $800{ }^{\circ} \mathrm{C}$ y $1000{ }^{\circ} \mathrm{C}$, pues sus propiedades mecánicas son propias de cerámicas porosas subcocidas, que no han alcanzado una adecuada reagregación e inicio de vitrificación.

Es en todo caso, a partir de $1100{ }^{\circ} \mathrm{C}$ donde comienzan a obtenerse valores análogos de resistencia mecánica a las pastas comerciales (en algunos casos superiores). Con estas temperaturas las posibles aplicaciones de estos materiales cerámicos son numerosas. A partir de $1250{ }^{\circ} \mathrm{C}$, debido al aumento de porosidad, se produce un descenso de la resistencia mecánica, aunque aumenta la vitrificación de las pastas, obteniéndose materiales cerámicos muy interesantes con posibles aplicaciones en procesos de filtrado de fluidos, productos para abrasión y pulido, entre otros.

\section{AGRADECIMIENTOS}

Este trabajo se ha desarrollado al amparo del convenio de colaboración Universidad de Granada (UGR), Grupo de Investigación HUM 629 y Universidad da Beira Interior, grupos de investigación C-MAST y C-MADE, donde se han realizado parte de los ensayos de materiales. Otros ensayos de materiales han sido realizados en Centro de Instrumentación Científica-UGR. Agradecemos la utilización del software XPowder, del Dr. Daniel Martín Ramos-UGR, así como al Dr. Sánchez Navas-UGR en tareas de DRX. Se agradece al Ministerio de Educación, Ciencia y Deporte la financiación recibida en el Programa de Formación del Profesorado Universitario FPU.

\section{BIBLIOGRAFÍA}

1. Silva, R.; Calvo Rebollar, M.; (1997): Mineralogía de Panasqueira, Bocamina, Núm. Especial: 12-27.

2. Durán Suárez, J.; Peralbo Cano, R.; Sorroche Cruz, A.; Montoya Herrera, J.; Castro Gomes, J.; Pereira da Silva, A.; (2011): Reutilización de esquistosgrauvacas procedentes de las minas de Panasqueira (Portugal) como arena de fundición, mediante moldeo en verde y otros usos refractarios, Fundipress, 28 (2): 46-50.

3. Montoya Herrera, J., Durán Suárez, J.A.; Peralbo Cano, R.; (2011): Diseño de nuevas pastas cerámicas y empleo en aplicaciones técnico-artísticas, Universidad de Granada, Granada, España.

4. Castro-Gomes, J.P.; Silva, A.P.; Peralbo Cano, R.; Durán Suárez, J.; Albuquerque, A.; (2012): Potential for reuse of tungsten mining waste-rock 
in technical-artistic value added products, J Clean Prod, 25: 34-41. http:/ / dx.doi.org/10.1016/j.jclepro. 2011.11.064.

5. Hevia, R.; Bustos, M.; (1998): Utilización de rocas volcánicas en productos cerámicos, Actas del VIII Congreso Argentino de Cerámica y II Iberoamericano de Cerámica, Vidrio y Refractarios, Buenos Aires, Argentina.

6. Pérez Rodríguez, G.A.; Guitián Riera, F.; de Aza Pendás, S.; (1999): Obtención industrial de materiales cerámicos a partir de lodos rojos del proceso Bayer, Bol. Soc. Esp. Ceram. Vidr., 38 (3): 220-226. http:/ / dx.doi. org/10.3989/ cyv.1999.v38.i3.962.

7. Caligaris, R.; Quaranta, N.; Caligaris, M.; Benavidez, E.; (2000): Materias primas no tradicionales en la industria cerámica, Bol. Soc. Esp. Ceram. Vidr., 39 (5): 623-626. http:/ / dx.doi.org/10.3989/ cyv.2000.v39.i5.779.

8. Hevia, R.P.; (2006): Materias primas no convencionales en cerámica, Cerámica y Cristal, 138: 50.

9. Santos Amado, J.D.; Malagón Villafrades, P.Y.; Córdoba Tuta, E.M.; (2011): Caracterización de arcillas y preparación de pastas cerámicas para la fabricación de tejas y ladrillos en la región de Barichara, Santander, Dyna, 78 (167): 53-61.

10. Mera, L.; Vásquez, P.; Bolaños, S.Y.; Oscullo, L.; (2010): Reutilización del vidrio de desecho para preparar esmaltes porcelánicos de primera capa, Revista Politécnica, 29 (1): 86-94.

11. Durán Suárez, J.; Montoya Herrera, J.; Peralbo Cano, R.; (2011): Diseño de nuevas pastas cerámicas a base de esquistos-grauvacas, Revista Internacional Cerámica, 123: 43-46.

12. Trilles-Lázaro, V.R.Y.; Allepuz, S.; (2011): Reutilización de vidrio reciclado y residuos cerámicos en la obtención de gres porcelánico. Eco-logik, Bol. Soc. Esp. Ceram. Vidr., 50 (2): 17-18. http:/ / dx.doi.org/10.3989/ cyv.2011. v50.i2.986.

13. Arancibia, J.R.H.; Alfonso, P.; García-Valles, M.; Martínez, S.; Parcerisa, D.; Canet, C.; Romero, F.M.; (2013): Obtención de vidrio a partir de residuos de la minería del estaño en Bolivia, Bol. Soc. Esp. Ceram. Vidr., 52 (3): 143-150. http:/ / dx.doi.org/ 10.3989/ cyv.192013.

14. Freestone, C. I.; Middleton, A. P.; (1987): Mineralogical applications of the analytical SEM in archaeology, Mineralogical Magazine, 51: 21-31. http:/ / dx.doi.org/10.1180/ minmag.1987.051.359.03.

15. Pappua, A.; Saxenaa, M.; Asolekar, S.R.; (2007): Solid wastes generation in India and their recycling potential in building materials, Build. Environ., 42 (6): 2311-2320. http:/ / dx.doi:10.1016/j.buildenv.2006.04.015.

16. Bernardo, E.; Esposito, L.; Rambaldi, E.; Tucci, A.; Hreglich, S.; (2008): Recycle of Waste Glass into "Glass-Ceramic Stoneware". J. Am. Ceram. Soc., 91 (7): 2156-2162. http: / / dx.doi:10.1111/j.1551-2916.2008.02460.x.

17. Martin, J. D. (2004): Using XPowder: A software package for Powder X-Ray diffraction analysis, Granada, Spain.

18. Jimenez Solís, C.; Barrera Solano, C.; Piñero, M.; Esquivias, L.; (1996): Uso de ultrasonidos para la optimizacíón del procesado de polvos cerámicos de YSZ, Bol. Soc. Esp. Ceram. Vidr., 35 (3): 181-186.

19. Moreno Gobbi, A.; Paolini, G.; Negreira, C.A.; (2001): Sistema ultrasónico automatizado y aplicaciones al estudio de transiciones de fase de cerámicas ferroeléctricas, Actas de las Jornadas SAM, Congreso CONAMET/AAS, Argentina.

20. Cantavella, V.; Llorens, D.; Mezquita, A.; Moltó, C.; Bhardwaj, M.C.; Vilanova, P.; Ferrando, J.; Maldonado Zagal, S.; (2006): Uso de la técnica de ultrasonidos para medir la densidad aparente de las baldosas en crudo y optimizar el proceso de prensado, Actas del IX Congreso Mundial de la
Calidad del Azulejo y Pavimento Cerámico QUALICER 2006, Castellón, España.

21. Pietroni, P.; Revel, G.M.; (2008): Ultrasonidos por láser para el control de calidad en la industria cerámica, Actas del X Congreso Mundial de la Calidad del Azulejo y Pavimento Cerámico QUALICER 2008, Castellón, España.

22. Arriola, I.; Gonzalo, O.; Bengoetxea, I.; (2012): Posibilidades del mecanizado por ultrasonidos rotatorio para fomentar el uso de las cerámicas técnicas en el mercado Español actual, Bol. Soc. Esp. Ceram. Vidr., 51 (4): 191-200. http:/ / dx.doi.org/ 10.3989/ cyv.282012.

23. Gómez Sánchez, A.; Tomba Martínez, A.G.; (2003): Resistencia a la rotura en compresión (CCS) de materiales refractarios monolíticos, Actas de las Jornadas SAM/Congreso CONAMET/Simposio Materia 2003, Chile.

24. Varela, P.G.; Cotella, N.G.; Oviedo, O.E.; Radevich, O.A.; Kohl, R.G.; (2003): Utilización del ensayo de compresión para la caracterización del barro utilizado en fundición de precisión, Actas de las Jornadas SAM/ Congreso CONAMET/Simposio Materia 2003, Chile.

25. Acosta, B.; Iglesias, I.; Yu, R.; Ruiz, G.; Acosta, A.; (2005): El ensayo de compresión diametral como alternativa a la caracterización mecánica de la cerámica de construcción, Anales de Mecánica de la Fractura, 22: 575-580.

26. Wang, F.; Gao, J.; Wang, H.; Chen, J.H.; (2010): Flexural strength and translucent characteristics of lithium disilicate glass-ceramics with different $\mathrm{P}_{2} \mathrm{O}_{5}$ content, Mater Design, 31 (7): 3270-3274. http: / / dx.doi.org/10.1016/j. matdes.2010.02.013.

27. Jia, L.; Xinghong, Z.; Zhi, W.; Wenbo, H.; Hua, J.; (2011): Microstructure and mechanical properties of hot-pressed $\mathrm{ZrB}_{2}-\mathrm{SiC}-\mathrm{ZrO}_{2} \mathrm{f}$ ceramics with different sintering temperatures, Mater Design, 34: 853-856. http: / / dx.doi. org/10.1016/ j.matdes.2011.07.023.

28. De Pablos, A.; Miranzo, P.; Osendi, M.I.; Romero, J.C.; Crespo, P.; Gargallo, M.A.; Bengoechea, M.A.; (2000): Estudio de las propiedades mecánicas de pavimentos cerámicos en crudo, Bol. Soc. Esp. Ceram. Vidr., 39 (5): 631-634. http:/ / dx.doi.org/ 10.3989/ cyv.2000.v39.i5.781.

29. Diedel, R.; Link, S.; (2006): Módulo de ruptura de las arcillas y pastas crudas. Preparación de las muestras y método de ensayo. Resultados prácticos de un ensayo interlaboratorio, Actas del IX Congreso Mundial de la Calidad del Azulejo y Pavimento Cerámico QUALICER 2006, Castellón, España.

30. Ferrer, M.; Peña Rodríguez, G.; Dulce, H.J.; (2011): Construcción y caracterización de cerámicas porosas a partir de espumas de poliuretano y barbotinas de arcillas rojas, Revista Colombiana de Física, 43 (2): 446-450.

31. Afanador García, N.; Guerrero Gómez, G.; Monroy Sepúlveda, R.; (2012): Propiedades físicas y mecánicas de ladrillos macizos cerámicos para mampostería, Ciencia e Ingeniería Neogranadina, 22 (1): 43-58.

32. Morales Güeto, J. (2005): Tecnología de los materiales cerámicos, Díaz de Santos, Madrid, España.

33. Winkler, E.M. (1975): Stone: Properties, durability in man's environment. Springer-Verlag, Wien, Austria. http://dx.doi.org/10.1007/978-3-70913819-9.

34. Sandoval, F.; Ibáñez, A.; (2000): Discusión sobre la influencia de la porosidad en la resistencia mecánica de las baldosas cerámicas, Bol. Soc. Esp. Ceram. Vidr., 39 (2): 255-258.

Recibido: $13 / 05 / 2014$

Recibida versión corregida: $08 / 12 / 2014$

Aceptado: 10/12/2014 